\title{
A Methodological Approach to Assessing the Possible Effect of Distributed Generation Expansion on Regional Energy Supply Systems
}

\author{
E. V. Galperova*
}

Melentiev Energy Systems Institute of Siberian Branch of Russian Academy of Sciences, Irkutsk, Russia

\begin{abstract}
One of the new challenges arising from the transition of the energy industry to the path of intelligent development is to assess the effect of distributed generation (DG) on the prospects for the development of regional energy supply systems. Such an assessment requires that the factors characterized by high uncertainty be taken into account. In this case, it is expedient to employ a combination of the optimization method with the Monte Carlo method. Such an approach has already been adopted in a model (computer program) developed at the Melentiev Energy Systems Institute, Siberian Branch of the Russian Academy of Sciences. This model is designed to determine the rational mix of new power plants (with investment risks assessed and factored in) and the likely cost of electricity generation in a given aggregated region. We propose using this model as a source of projected data for an approximate assessment of the DG expansion, given the projected conditions for the energy sector and electric power industry development. It may also provide the basis for an array of research tools for relevant studies. The new toolkit requires a more detailed representation of the administrative division and the inclusion of consumers with their sources of electric power generation in the generating capacity. Although such an estimate is approximate, it can give an overall idea of the extent to which the cost and demand for electricity may vary under different options for the DG expansion in a region.
\end{abstract}

Index Terms: projections, distributed generation, consumers, energy carriers, demand, energy sector, electric power industry, optimization, uncertainty.

\footnotetext{
${ }^{*}$ Corresponding author.

E-mail: galper@isem.irk.ru
}

http://dx.doi.org/10.38028/esr.2021.02.0006

Received June 16, 2021. Revised June 21, 2021.

Accepted July 03, 2021. Available online July 23, 2021.

This is an open access article under a Creative Commons Attribution-NonCommercial 4.0 International License.

C) 2021 ESI SB RAS and authors. All rights reserved.

\section{INTRODUCTION}

The well-established practice of making projections for Russia's energy sector [1-3] focuses primarily on determining the structure of energy carriers production and the volume of fuel and energy consumption in the sector itself, so as to meet a given demand of the economy for energy carriers, such demand being exogenous to the sector. Such studies fail to consider the possible adjustment effect of consumption on the energy development options, for example, due to the emergence of the consumer's ability to change their energy consumption when prices of different types of energy change or to have self-generation and/or storage facilities. These new opportunities may entail changes in the structure or volume of the initially assumed energy demand and affect the optimization of the energy sector.

At present, the global energy system is rapidly transitioning from an electric power system built on conventional centralized generation with a unidirectional flow to an integrated and hybridized grid containing elements of both centralized generation and distributed energy resources [4]. According to [5], the technologies of distributed energy (distributed energy resources (DER)) are understood internationally as covering the following:

- distributed generation;

- demand response;

- energy efficiency management;

- microgrids;

- distributed energy storage systems;

- electric cars.

The basic property of all these technologies is proximity to the energy consumer.

As stated in [6 p. 272], «distributed generation is the generation of electricity/heat at the place of its consumption. Having no grid eliminates the losses (costs) of electricity/heat transmission, which implies the presence of many consumers that generate heat/electricity for their own needs and transfer its surplus to a common grid.»

Small-scale distributed energy has been a leading trend in the world for several decades now. Experts estimate that this trend will continue in the coming decade. Navigant Research predicts that by 2026 , the amount of distributed 
Preliminary stage. Analysis of available projections

\section{Projection time frame stages} $15-20$ years

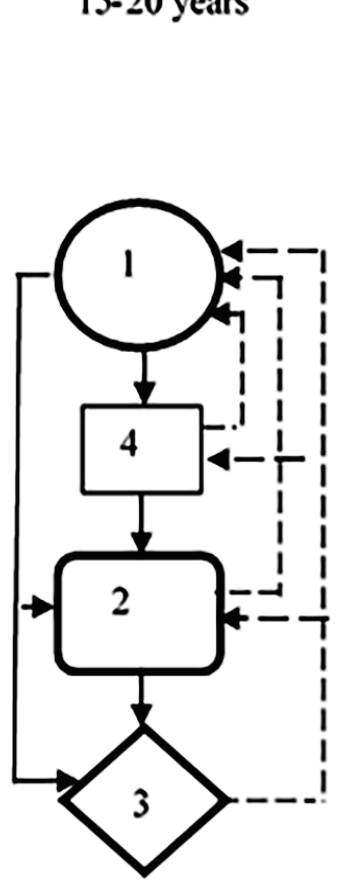

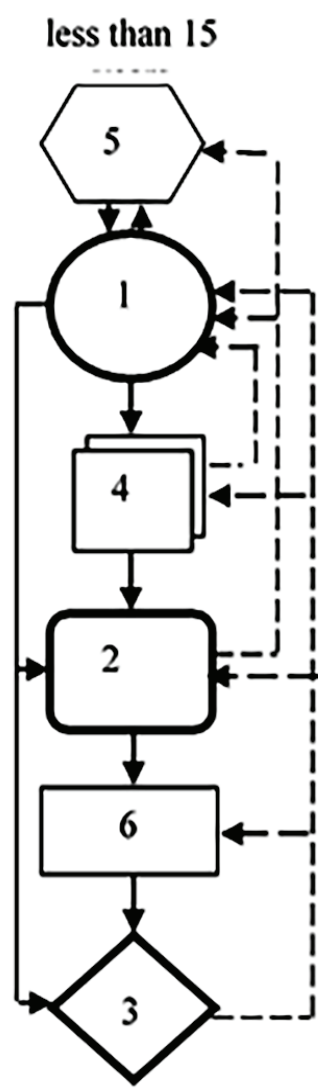

1 - prospects for the energy sector; 2 - a study of the state of regional energy markets (demand and prices); 3 - an assessment of barriers and threats to energy security; 4 - development of individual industries of the energy sector; 5 - the interaction with the macroeconomic system; 6 - investment policy of energy companies.

Fig. 1. The structure and relationships of problems to be solved at different time stages of the study of the long-term energy development options. Source: [1].

generation capacity commissioned worldwide will exceed the amount of centralized generation by a factor of three. According to the data published by the SCC Research company, the size of the global market for distributed generation technologies in 2015 was $\$ 65.8$ billion. [7]. The International Energy Agency estimates that distributed energy can provide up to $75 \%$ of new connections in the course of global electrification by 2030 [5].

There is virtually no accurate data on the share of distributed generation and its dynamics in the energy industry of Russia. In [5], the total capacity of distributed generation facilities in Russia as of 2017 was estimated at $23-24 \mathrm{GW}$ or $9-9.5 \%$. The studies presented in [5] demonstrate that given the full utilization of the distributed energy potential it is possible to meet the entire projected demand for generating capacity of 54-66 GW in the Unified Energy System of Russia by 2035.

\section{LITERATURE REVIEW}

Research into various aspects of distributed generation development has become a relevant topic in recent years. In [8-13], the authors consider the main advantages, system-wide effects, and issues related to the connection of distributed energy sources to distribution networks. Studies [14-16] cover the operation of power grids with DG, including power system protection, hourly load, and electric power quality of distributed generation devices [17-20]. In [21-23], the authors investigate the security of electric power systems with distributed generation in terms of cascading failures and present the models for determining the limit operating conditions in power grids and methods for assessing the operating parameters of energy service areas with distributed generation facilities. Some studies address the reliability of energy supply systems $[24,25]$ and examine the possibility of ensuring reliable electric power supply to consumers through the construction of distributed generation facilities [26-29]. Furthermore, distributed energy generation is viewed as a factor of energy security improvement and sustainable development of regions [30-32]. Despite the significant body of published research covering various issues of distributed generation expansion, it proved impossible to find the studies on its effect on electricity demand, its price, and generation structure. 


\section{PROPOSED METHODOLOGICAL APPROACH}

The Melentiev Energy Systems Institute, SB RAS (ESI SB RAS), has developed and has been continuously improving a multi-stage methodological approach to enhance the validity of long-term projections of the national energy sector development. This approach assumes the existence of problems varying in their importance and complexity and ways to solve them at different time stages of the projection time frame (Figure 1).

We have built a methodological toolkit (a pool (set) of various types of models) for projection studies [33, 34]. The models are not linked to each other by automatic procedures, which allows solving individual problems, for which the models were originally developed, and employing them as building blocks of systems to be used for calculations. In this case, the results of solving some models are used as input data for others. As new problems arise, the pool is supplemented with new models or modifications of existing ones.

One of the new problems arising with the transition of the energy industry to the path of intelligent development is a projection of the possible effect of distributed generation (DG) on the projected structure and cost of electricity generation and the demand for it in a region. A prerequisite for solving it lies in considering the region-specific energy and economic development conditions and the quality of the information used. Earlier studies [35] attested to a significant disparity in the cost of electricity generation by region and its dependence on the type of probability distribution within the ranges of the assumed values of input data (Table 1).

Methodological approaches to assessing the energy development options depend on the given time frame and the objectives of the projection studies. The uncertainty increases as the projection time frame extends further into the future. Hence, the decision on strategic directions of energy industry development looking ahead 20 years or more will have less stringent requirements for the accuracy of the results, the degree of detail with respect to the administrative divisions, and the factors to be considered.

The assessment of the possible effect of distributed generation on the projected structure, production cost, and demand for electricity in a region is most important when the projections extend up to 15 years into the future because it is this period that predetermines the conditions for the modernization of regional energy supply systems.

A specific feature of the assessment is the need to consider the diversity of behaviors and ways of selfgeneration in different groups of consumers, which requires a more detailed treatment of the administrative division given the conditions for the development of individual regional power systems, the characteristics of consumers, electrical load curves, and others. All these parameters are highly uncertain, which is why the Monte Carlo method along with the optimization method may prove appropriate for the assessment. This approach is used in the MISSEL model developed at the ESI SB RAS [35]. The model designed determines a rational mix of new power plants (with investment risks assessed and factored in) and the likely cost of electricity generation in aggregated regions (Federal districts and/or interconnected power systems) for a time horizon of up to 15 years.

The methodological principles and results of the studies based on the MISS-EL model are proposed as a framework to be used for the approximate assessment of the DG effect on the development of regional energy supply systems. It is supposed to use model (1) as a source of projected data on the conditions for the electric power supply systems expansion and (2) as a basis for the new toolkit development. The toolkit should factor in the projection

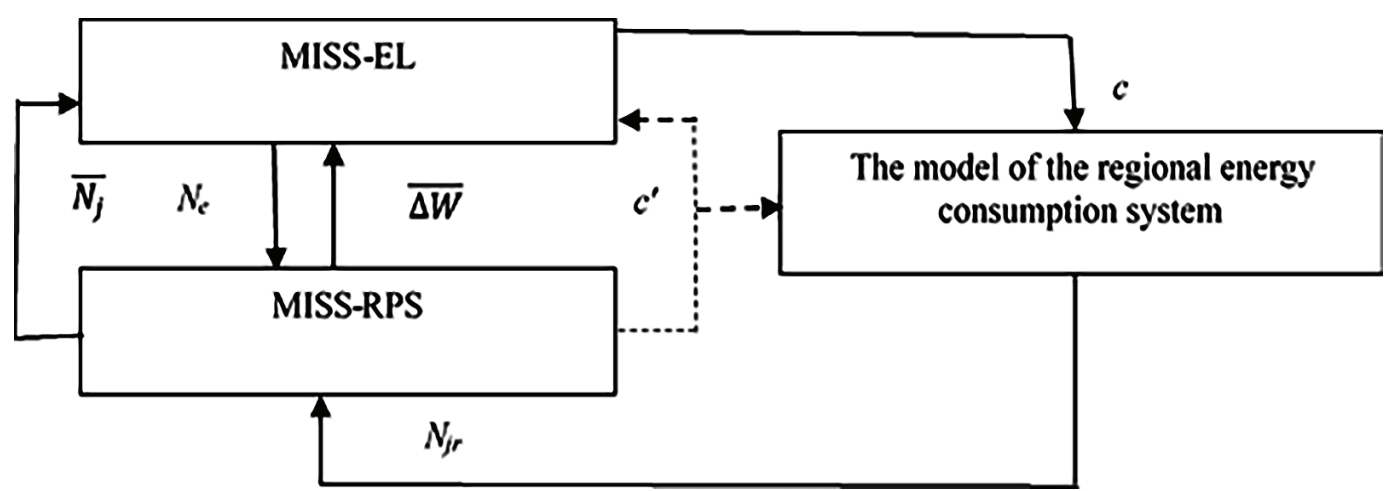

Fig. 2. The overall flow diagram of the proposed approach to assessing the effect of the DG expansion on regional energy supply systems. Source: developed by the author.

TABLE 1. Effect of regional differences and the nature of uncertainty in the input data on the cost of electricity generation in the interconnected power systems (IPSs) of European Russia as compared to the Ural IPS, \%

\begin{tabular}{ccccc}
\hline \hline \multirow{2}{*}{ The nature of information uncertainty } & & & IPS & \\
\cline { 2 - 5 } & Northwestern & Central & Middle Volga & Southern \\
\hline Normal distribution & 105 & 103 & 111 & 105 \\
Uniform distribution & 110 & 110 & 118 & 114 \\
\hline \hline
\end{tabular}


time frame, the required level of detail with respect to the administrative division, the characteristics of consumers, and the conditions and opportunities for the DG expansion. In essence, the MISS-EL model should serve as a basis for a new model of the regional power system (MISS-RPS). The flow diagram of the proposed approach to assessing the effect of the DG expansion on regional energy supply systems and the main relationships between the models are shown in Figure 2.

In the MISS-RPS model, DG is represented as an additional source of electric power generation. The functional of such a model for the given region consists of the following: costs of electricity generated by centralized sources (data obtained from the MISS-EL model) detailed for individual administrative divisions $r$ (by Federal entity, by district, by city, etc.) of a region, costs of electricity generated by DG units (data from the regional energy consumption model), and the tariff for electricity transmission from centralized and distributed sources:

$$
F=\sum_{r} \sum_{e} c_{e r} N_{e r} h_{e r}+\sum_{r} \sum_{j} c_{j r} N_{j r} h_{j r}+\sum_{e} \sum_{j} T_{e j} W_{e j} \rightarrow \min ,
$$

where $c_{e r}$ - discounted costs of electricity generation at a power plant of type e (cent/kWh) in territory $r, N_{e r}$ - the installed capacity of a power plant of type e $(\mathrm{kW})$ in the administrative division $r, h_{e r}$ - the number of hours of the installed capacity utilization at a power plant of type e (hour) in territory $r, \mathrm{c}_{j r}$ - discounted costs of electricity generation by a DG unit of type $j$ (cent/kWh) in the administrative division $r, N_{j r}$ - the installed capacity of a DG unit of type $j(\mathrm{~kW})$ in the administrative division $r, h_{j r}-$ the number of hours of the installed capacity utilization of a DG unit of type $j$ (hour), $T_{e j}$ - the tariff for electricity transmission from a power plant of type $e$ and a DG unit of type $j$ (cent/ $\mathrm{kWh}), W_{e j}-$ the amount of electricity transmitted from a power plant of type $e$ and DG unit of type $j(\mathrm{kWh})$.

The main constraints in the MISS-RPS model are as follows:

available potential for the expansion of DG units of type $j$

$$
0 \leq N_{j} \leq \bar{N}_{j}
$$

possible commissioning of new power plants of type e

$$
N_{e} \leq N_{e} \leq \bar{N}_{e}
$$

the projected level of electricity consumption

$$
\underline{W} \leq W \leq \bar{W}
$$

where

$$
W=\sum_{e} N_{e} h_{e}+\sum_{j} N_{j} h_{j}
$$

The calculation of the values of economic performance indicators of $\mathrm{DG}$ in the model of regional energy consumption involves the analysis of the following: what are the sectors of the economy (residential, commercial, industrial) that have (are planned to have) the DG units, what is their possible generation capacity, what is the cost of electricity generation at these facilities, and which part of the electrical load curve they can help to handle. Specific capital and operating costs are determined for each sector separately, given their dependence on the scale of DG expansion.

Values of fuel prices, technical and economic performance parameters of plants and constraints are represented as ranges of their prospective values with the possibility of setting the type of probability distribution within these ranges (normal, uniform, exponential, etc.). The Monte Carlo method allows determining a set of well-balanced solutions under different combinations of characteristics of future conditions. This set is used to form an option of the electricity generation structure at its minimum cost under the assumed conditions.

The study presupposes the following sequence:

1. The MISS-EL model is calibrated to match the given scenario of economic and energy development. Calculations based on the model determine the likely mix of new capacity additions $\left(N_{e}\right)$ and the cost of electricity generation $(c)$ in the included IPSs. The results thus obtained serve as the input data for the MISS-RPS model.

2. In the MISS-RPS model, the capacity added is detailed for administrative divisions of the region in question and is supplemented by the DG capacity of different consumer categories $\left(N_{j r}\right)$. The latter is determined in the model of the regional energy consumption system in terms of the electricity production cost obtained by MISS-EL $(c)$.

3. Calculations based on the MISS-RPS model clarify the cost of electricity generation $c^{\prime}$ in the considered region, given its distinctive features. Furthermore, they allow one to determine the potential of substituting centrally commissioned capacity $\left(N_{e}\right)$ for DG capacity

( $\bar{N}_{j}-$ the upper limit of DG capacity) and the volume of electricity generation $(\overline{\Delta W})$ by the DG capacity.

4. Based on contingency calculations (different scenarios of DG expansion), we arrive at the dependencies of prices and demand for electricity on the scale of the DG expansion in a region.

Results of calculations based on the MISS-RPS model in the form of a decrease in demand for electricity $(\overline{\Delta W})$ in the region under consideration can be used to clarify and assess possible changes in the structure and cost of electricity generation in the studies performed based on the MISS-EL model.

\section{CONCLUSION}

The development of distributed energy is a leading global trend, contributing to the transition from the conventional unidirectional arrangement of energy systems to their new integrated and hybridized types that combine large-scale centralized energy sources with distributed ones. In this context, one of the challenges arising in long-term studies of feasible options for the electric power industry and the energy sector is to assess the effect of the DG adoption scale on the structure of electricity generation, its cost, and 
demand for electricity in a region.

The methodological approach and toolkit proposed for solving this problem rely on a combination of the methods of optimization and Monte Carlo simulation and enable contingency calculations in terms of the quality of available information and assessment of changes in the cost of electricity and its demand for different options of the DG expansion in a region.

Such an estimate is approximate, but it can provide an overall idea of the extent of the DG impact on the development of regional energy supply systems, which will be instrumental in improving the validity of projections of the electric power industry and the energy sector development.

\section{ACKNOWLEDGMENT}

The research was conducted under State Assignment Project (no. FWEU-2021-0003) of the Fundamental Research Program of the Russian Federation 2021-2030 (reg. number AAAA-A21-121012090014-5). Some results were obtained with partial support by RFBR project number 20-010-00204.

\section{REFERENCES}

[1] Yu. D. Kononov, Approaches to improve the validity of long-term projections of the energy sector. Novosibirsk: Nauka, 2015. 147 p. (in Russian)

[2] Energy systems analysis: methodology and research findings, A.A Makarov and N.I. Voropai, Eds. Moscow: Energy Research Institute RAS, 2018, 309 p. (In Russian)

[3] A.A. Makarov. "Half a century of the systems analysis of the energy industry development in the USSR and Russia - and what is next? (review)," Thermal Engineering, no. 12, pp. 5-14, 2020. (in Russian)

[4] N.I. Voropai, "Distributed generation in electric power systems," International Scientific and Practical Conference «Small-scale generation-2005,» Available at: http://www.combienergy.ru/ stat/983-Raspredelennaya-generaciya-velektroenergeticheskih-sistemah (accessed 03.02. 2021). (in Russian)

[5] Distributed energy in Russia: Potential for development. Energy Centre of the SKOLKOVO Moscow Business School, 89 p. Available at: https://energy.skolkovo.ru/downloads/documents/ SEneC/Research/SKOLKOVO EneC DER3.0_2018.02.01.pdf (accessed 03.02. 2021). (in Russian)

[6] The innovation-driven electric power sector-21, V.M. Batenin, V.V. Bushuev, and N.I. Voropai, Eds. Moscow: Energiya Publishing Center, 2017, 584 p. (in Russian)

[7] A. Khokhlov, F. Veselov, "Internet of Energy: how distributed energy will influence safety, electricity prices, and the environment." Available at: http:// www.forbes.ru/biznes/351485-internet-energy- kak-raspredelennaya-energetika-povliyaet-nabezopasnost-ceny-na. (accessed 03.02. 2021). (in Russian)

[8] Yu.E. Gurevich, P.V. Ilyushin, Special aspects of calculations of operation modes in the energy service area with distributed generation: a research monograph. Nizhny Novgorod: Nizhny Novgorod Branch of the Russian Presidential Academy of National Economy and Public Administration, 2018, 280 p. (in Russian)

[9] P.V. Ilyushin, Prospects for application and outstanding issues of integration of distributed energy sources into power grids: a research monograph. Moscow: NTF «Energoprogress», 2020, 116 p. DOI: 10.34831/EP.2020.260.8.001 (in Russian)

[10] L. Mehigan, J.P. Deane, B.P.O. Gallachoir, V. Bertsch, "A review of the role of distributed generation in future electricity systems," Energy, vol. 163, pp. 822836, 2018.

[11] C. Mateo, P. Frías, K. Tapia-Ahumada, "A comprehensive techno-economic assessment of the impact of natural gas-fueled distributed generation in European electricity distribution networks," Energy, vol. 192, pp. 116523, 2020.

[12] S.P.S. Matosa, M.C. Vargas, L.G.V. Fracalossi, L.F. Encarnaç ao, O.E. Batista, "Protection philosophy for distribution grids with high penetration of distributed generation," Electric Power Systems Research, vol. 196, pp. 107203, 2021.

[13] Ali Ehsan, Qiang Yang, "Optimal integration and planning of renewable distributed generation in the power distribution networks: A review of analytical techniques," Applied Energy, vol. 210, pp. 44-59, 2018.

[14] B.A. Kosarev, G.A. Koshchuk, V.K. Fedorov, O.A. Lysenko, "Optimization of the operation of the electrical engineering system with distributed generation," Actual Issues of Energy, no. 1, pp. 99103, 2019. (in Russian)

[15] N.A. Gorshkova, Yu.E. Gurevich, P.V. Ilyushin, "Promising directions in the automation of distributed generation facilities during their integration into distribution networks," Relejnaya zashchita $i$ avtomatizatsiya, no. 1 (10), pp. 48-55, 2013. (in Russian)

[16] Chenjie Maa, Johannes Dasenbrocka, J.-Christian Töbermanna, Martin Braun, "A novel indicator for evaluation of the impact of distributed generations on the energy losses of low voltage distribution grids," Applied Energy, vol. 242, pp. 674-683, 2019.

[17] M.V. Sharygin, A.L. Kulikov, V.Yu. Vukolov, A.A. Petrov, "Adaptive power system protection for power grids with distributed generation sources," Proceedings of the Russian Academy of Sciences. Power Engineering, no. 3, pp. 60-68, 2020. DOI: $10.31857 / \mathrm{S} 000233102003005 X$ (in Russian)

[18] A.V. Kirpikov, I.L. Kirpikova, V.P. Oboskalov, "Loading strategies for distributed generation devices 
during the day," Industrial Power Engineering, no. 4, pp. 12-15, 2014. (in Russian)

[19] E.B. Solntsev, A.M. Mamonov, A.N. Fitasov, S.A. Petritskij, A.A. Sevostyanov, "Analysis of electric power quality (voltage fluctuations) in distributed generation," Energobezopasnost' $i$ Energosberezhenie, no. 3, pp. 37-40, 2019. (in Russian)

[20] G.B. Guliev, N.R. Rakhmanov, "Fuzzy logic controller for reactive power and voltage control in distributed generation networks," Elektro. Elektrotekhnika, elektroenergetika, elektrotekhnicheskaya promyshlennost', no. 2, pp. 47-52, 2014. (in Russian)

[21] Ch. Sh. Fam, N.I. Voropai, "The study of the security of electric power supply systems with distributed generation and cascading failures factored in,» Elektrichestvo, no. 12, pp. 14-20, 2013. (in Russian)

[22] Yu.N. Bulatov, A.V. Kryukov, A.V. Cherepanov, "Mathematical models for determining the limit operating conditions in power grids with distributed generation installations," Science Bulletin of Novosibirsk State Technical University, no. 4 (80), pp. 17-36, 2020. (in Russian)

[23] A.L. Kulikov, P.V. Ilyushin, P.S. Pelevin, “Application of discriminatory methods for estimation of operating parameters of energy service areas with distributed generation facilities," Elektrichestvo, no. 7, pp. 2235, 2019. (in Russian)

[24] B.V. Papkov, V.L. Osokin, "Special aspects of the assessment of structural reliability of systems with distributed generation facilities," Proceedings of the Russian Academy of Sciences. Power Engineering, no. 2, pp. 75-84, 2020. DOI: $10.31857 /$ S0002331020020090. (in Russian)

[25] S.A. Nekrasov, "Improving the reliability and availability of power supply of Russian cities based on distributed generation," NRE, no. 9, pp.15-25, 2012. (in Russian)

[26] P.V. Ilyushin, Yu.N. Kucherov, "Approaches to assessment of the possibility of ensuring reliable electric power supply to consumers by means of construction of distributed generation facilities," Elektro. Elektrotekhnika, elektroenergetika, elektrotekhnicheskaya promyshlennost', no. 5, pp. 2-7, 2014. (in Russian)

[27] D.A. Chechushkov, T.Yu. Panikovskaya, E.A. Bun'kova, "Method of optimal placement of distributed generation sources to improve the reliability of electricity supply," Industrial Power Engineering, no. 9, pp. 17-21, 2014. (in Russian)

[28] A.V. Varganova, Yu.M. Bajramgulova, I.N. Goncharova, O.A. Krotkova, "Feasibility study of the installation site of distributed generation sources," Electrotechnical Systems and Complexes, no. 3 (44), pp. 68-72, 2019. (in Russian)

[29] Surender Singh Tanwara, D.K. Khatod, "Technoeconomic and environmental approach for optimal placement and sizing of renewable DGs in the distribution system," Applied Energy, vol. 127, pp. 52-67, 2017.

[30] L.L. Moiseev, V.N. Slivnoy, "Distributed energy generation: a factor in increasing energy security of a region," Polzunovsky Vestnik, no. 1, pp. 226-229, 2004. (in Russian)

[31] S. Mayorov, "Distributed stand-alone generation as a basis for energy security," Energonadzor, no. 5 (81), pp. 8, 2016. (in Russian)

[32] S.P. Filippov, M.D. Dil'man, P.V. Ilyushin, "Distributed generation and sustainable development of regions," Thermal Engineering, no. 12, pp. 4-17, 2019. (in Russian)

[33] E.V. Galperova, "Employing a model pool for long-term projections of market demand for energy carriers," Informatsionnye $i$ Matematicheskie Tekhnologii v Nauke i Upravlenii, no. 4-2, pp. 17-27, 2016. (in Russian)

[34] Yu.D. Kononov, E.V. Galperova, D.Yu. Kononov, A.V. Lagerev, O.V. Mazurova, V.N. Tyrtyshny. Methods and models for projections of energyeconomy interactions. Novosibirsk: Nauka, 2009, 178 p. (in Russian)

[35] Yu.D. Kononov, D.Yu. Kononov, "The economic component of energy security and methodological approaches to its assessment," National Interests: Priority and Security, vol. 5, no. 6, pp. 1086-1096, 2019. (in Russian)

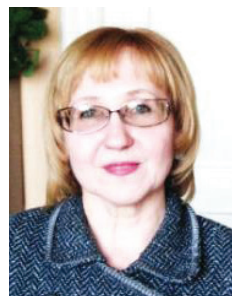

E. V. Galperova - Ph. D., Associate Professor, Senior researcher of Melentiev Energy Systems Institute of Siberian Branch of the Russian Academy of Sciences, Russia, Irkutsk. Her main research interests are longterm forecasting of regional energy markets and energy consumption patterns, projections of energy demand in terms of technological patterns, standards of living, price indicators. 